\title{
Experimental study and multi-physics modelling of concrete under
}

\author{
supercritical carbonation
}

\author{
Hao Bao a,b , Min $\mathrm{Yu}^{\mathrm{a},{ }^{*}}$, Lihua $\mathrm{Xu}^{\mathrm{a}}$, Mohamed Saafic, Jianqiao $\mathrm{Ye}^{\mathrm{c}, *}$ \\ a. School of Civil Engineering, Wuhan University, Wuhan, China \\ b. College of Civil Engineering \& Architecture, China Three Gorges University, Yichang, China \\ c. Department of Engineering, Lancaster University, Lancaster LA1 4YR, UK \\ *Correspondence author: ceyumin@whu.edu.cn (M. Yu), j.ye2@lancaster.ac.uk (J. Ye)
}

\begin{abstract}
This paper presents both experimental study and multi-physics modelling of supercritical carbonation of concrete. A novel mathematical model is proposed to simulate random distribution of coarse aggregates in concrete. Supercritical carbonation tests of concrete are carried out and the measured carbonation depth is compared with the simulation results. On the basis of previous research on random field of porosity and supercritical carbonation of cement mortar, a new supercritical carbonation model is developed to study the effect of randomly distributed coarse aggregates and porosity on the irregularities of carbonation depth of concrete. The effect of the type, volume fraction and gradation of coarse aggregates and the porosity of ITZ on the distribution of irregular carbonation depth are also studied. The results demonstrate that the proposed twodimensional random coarse aggregates model can be used satisfactorily to generate different types, volume fraction and gradation of coarse aggregates with the designed mix proportion within a confined space. The method provides a better and more realistic predictive model for simulating carbonation depth of concrete due to random distribution of coarse aggregates and porosity.
\end{abstract}

Keywords: Carbonation depth, Concrete, Irregularity, Random aggregate model, Supercritical carbonation.

\section{Introduction}

It is well known that carbonation is one of the major processes that results in corrosion of steel reinforced concrete. In order to understand the carbonation mechanism of concrete, significant research has been carried out recently to study the complex carbonation process ${ }^{[1-4]}$, including the experimental investigations on general carbonation mechanism ${ }^{[5]}$, carbonation of self-compacting concrete ${ }^{[6-9]}$, the theoretical model proposed to predict carbonation depth of concrete based on experiment results ${ }^{[10]}$ and the life prediction model [11]. Numerical investigations were carried out also to simulate carbonation tests ${ }^{[12]}$. A literature review has shown that there exist extensive experimental studies on natural and accelerated carbonation of concrete. There are also analytical and numerical studies aiming to characterise the transport and reaction of $\mathrm{CO}_{2}$ in cement and/or concrete materials. In general, natural and accelerated carbonations of concrete are a slow process of chemical reaction, which is prohibitively time consuming for laboratory tests.

Supercritical carbonation technique provides a promising way for concrete carbonation research. Under supercritical conditions, i.e., when the pressure and temperature exceed $7.38 \mathrm{MPa}$ and $304.12 \mathrm{~K}$, respectively [13], cement-based materials can be carbonated far quickly, so that researchers can assess the impact of carbonation on the materials within a realistic time frame. Moreover, the technique has been widely used in, e.g., $\mathrm{CO}_{2}$ capture and storage to absorb the carbon dioxide from the atmosphere ${ }^{[14,15]}$, material surface curing, 
improving compactness of materials ${ }^{[16-18]}$, enhancing mechanical property and durability of fibre reinforced cementitious composites ${ }^{[19,20]}$, recycling concrete ${ }^{[21,22]}$, and solidification and stabilization of heavy metals and hazardous materials ${ }^{[23-26]}$ in concrete.

Carbonation depth is a significant parameter relative to carbonation rate and durability of concrete. Naturally, the distribution of carbonation depth is irregular with distinctive minimum and maximum along the boundary of a carbonation zones under both natural ${ }^{[27]}$ and supercritical ${ }^{[28-30]}$ conditions. However, the irregularities cannot been predicted by most carbonation models that assumed all cement-based materials are homogenous ${ }^{[31]}$, resulting in uniform carbonation depth ${ }^{[32]}$. In fact, the topography of carbonation depth is affected by the presence of coarse aggregate ${ }^{[12,33,34]}$, cracks ${ }^{[35-37]}$, porosity of cement ${ }^{[29,30,38]}$, porosity of the Interfacial Transition Zone (ITZ) ${ }^{[39,40]}$ and compositions of concrete ${ }^{[41,42]}$. To statistically study the distribution of irregular carbonation depth, Alahmad, et al. ${ }^{[43]}$ showed that penetration and diffusion of $\mathrm{CO}_{2}$ were significantly affected by cracks in cement mortar. Bao, et al. ${ }^{[30]}$ proposed a numerical model to simulate randomly distributed carbonation depth of cement mortar. Papadakis, et al. ${ }^{[41]}$ found that composition of cementbased materials has noticeable effect on the carbonation process. It was concluded that the heterogeneity of concrete contributed mostly to the observed randomness ${ }^{[44]}$. Moreover, Han, et al. ${ }^{[12]}$ studied the effects of cracks, ITZ and aggregates on carbonation of concrete. However, simulating irregularities of supercritical carbonation depth of concrete by considering random distribution of both coarse aggregates and porosity has not been well studied so far.

This paper is an extension of the authors' previous work ${ }^{[29,30]}$ on supercritical carbonation depth of cement mortar, where random nature of porosity was included in a multi-physics model. To apply a similar approach to concrete, the effects of randomly distributed aggregates, including their locations, sizes and types, have to be properly considered. To this end, a new 2-D statistical model is proposed to generate random distribution of aggregates. A modified supercritical carbonation model considering both coarse aggregates and porosity in concrete is proposed and validated against the test results. The model is further used to study the effect of coarse aggregates and porosity distribution of cement paste and ITZ on the distribution of carbonation depth of supercritically carbonated concrete.

\section{Experimental investigation}

\subsection{Preparation of concrete specimens}

Concrete cubes of side $100 \mathrm{~mm}$ were cast with the composition shown in Table 1. The range of the crushed stone aggregates was from 5 to $20 \mathrm{~mm}$. After casting, the surfaces of the specimens were carefully smoothed and covered with plastic films. The cubes were removed from the molds after $24 \mathrm{hrs}$. All the cubes were cured then for 28 days in a standard curing room. Amongst the cubes, eighteen were prepared for carbonation tests and one for mercury injection apparatus (MIP) test. The eighteen cubes were divided further into three groups for supercritical carbonation. Small samples with dimension of millimeters were taken from the concrete cubes. The samples were immersed into absolute ethyl alcohol to prevent further hydration. The samples were dried in a vacuum heating oven at $90^{\circ} \mathrm{C}$ until weight stability was reached. The MIP test using AutoPore IV 9500 shown that the porosity of the concrete before carbonation was $12.8 \%$. 
Table 1. Mixture proportions

\begin{tabular}{|c|c|c|c|c|}
\hline & Cement $\left(\mathrm{kg} / \mathrm{m}^{3}\right)$ & Water $\left(\mathrm{kg} / \mathrm{m}^{3}\right)$ & Sand $\left(\mathrm{kg} / \mathrm{m}^{3}\right)$ & Crushed stone aggregate $\left(\mathrm{kg} / \mathrm{m}^{3}\right)$ Water-binder ratio \\
\hline Concrete & 417.2 & 208.6 & 612.1 & 1162.1 \\
\hline
\end{tabular}

\subsection{The closed-cycle carbonation system}

The improved closed-cycle carbonation system ${ }^{[30]}$ was applied in the supercritical carbonation tests of concrete. A schematic diagram of the test is shown in Fig.1. The water circulating in the chiller and the heater are, respectively, for cooling and heating-up the reactor. The pressure and temperature in the reactor were monitored constantly by sensors that are mounted at various positions. The surrounding relative humidity were also constantly monitored and recorded.

The specimens were divided into three groups for supercritical carbonation of 3, 4 and 5 hours, respectively.

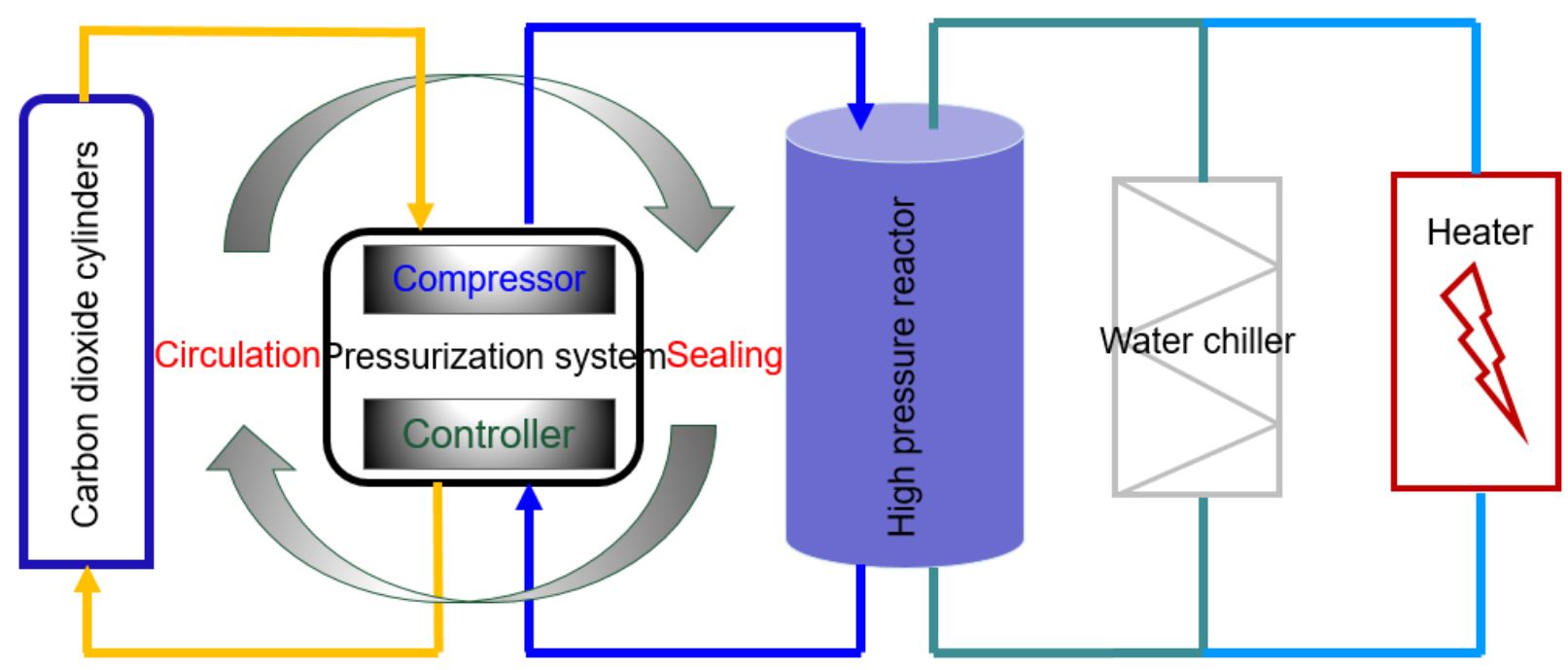

Fig. 1. Schematic diagram of closed-cycle carbonation system

\subsection{Carbonation results of concrete}

The concrete cubes were taken out of the reactor after the supercritical carbonation test was completed. The concrete specimens were cut into two halves. The freshly cut surface was cleaned and sprayed with phenolphthalein indicator that displayed pink color over any non-carbonated zone. Figs. 2 (a-c) show the scanned images from the three groups that were super-critically carbonated for 3, 4 and 5 hours, respectively.

Fig. 2 clearly shows that the profile of the carbonation depth is irregular and of a random nature.

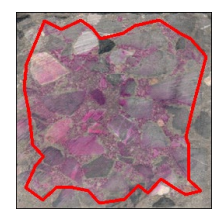

C-CON-1

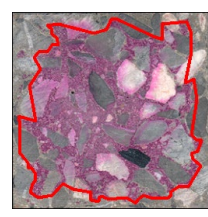

C-CON-2

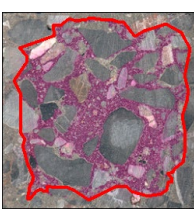

C-CON-3

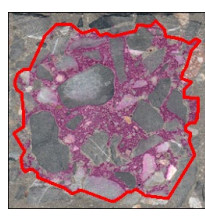

C-CON-4

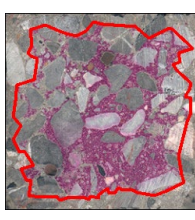

C-CON-5

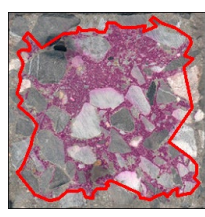

C-CON-6

a) Group 1: 3 hours for concrete 


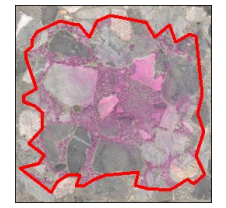

C-CON-7

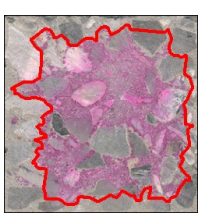

C-CON-13

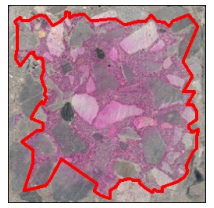

C-CON-8

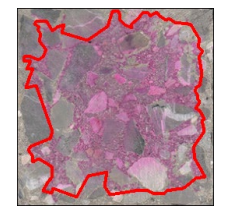

C-CON-9

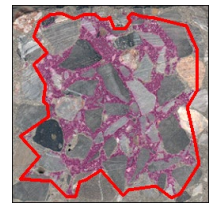

C-CON-10

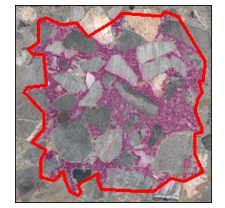

C-CON-11

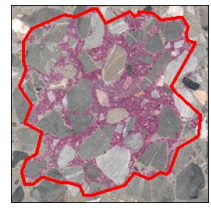

C-CON-12

b) Group 2: 4 hours for concrete

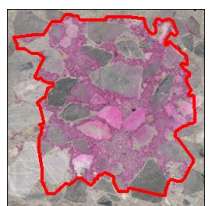

C-CON-14

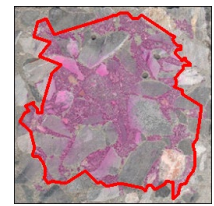

C-CON-15

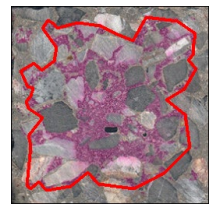

C-CON-16

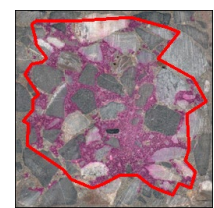

C-CON-17

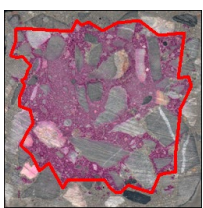

C-CON-18

c) Group 3: 5 hours for concrete

Fig. 2. Test results of supercritical carbonation of concrete

\subsection{Analysis of the test results}

The image processing technique proposed by the authors in ${ }^{[30]}$ was used in this Section to measure the carbonation depth. As shown in Fig. 2, the distances from the carbonation boundary to the edge of the cube were measured from the scan image processed by Matlab as an assembly of pixels and are presented as the carbonation depth. Table 2 shows the average values of the average, maximum, minimum and variances of carbonation depths of the respective groups. Table 2 also shows that as expected when the carbonation time increases, the average, maximum, minimum carbonation depths and their variance also increase.

Table 2. Statistical result of experimental carbonation depth

\begin{tabular}{llll}
\hline Group & Group 1 & Group 2 & Group 3 \\
\hline Supercritical carbonation time, $T(\mathrm{~h})$ & 3 & 4 & 5 \\
\hline Average carbonation depth, $\mu_{l}(\mathrm{~mm})$ & 8.3 & 8.6 & 10.3 \\
Maximum carbonation depth, $D_{\max }(\mathrm{mm})$ & 18.3 & 18.4 & 22.8 \\
Minimum carbonation depth, $D_{\min }(\mathrm{mm})$ & 2.2 & 2.5 & 2.8 \\
Variance, $v_{l}\left(\mathrm{~mm}^{2}\right)$ & 10.7 & 14.8 & 21 \\
\hline
\end{tabular}

\section{Numerical investigation}

In order to study the effects of porosity and coarse aggregates, including their types, volume fractions and gradations on the irregular carbonation depth, the test results were used in this Section to verify the numerical multi-physics model that was developed to simulate supercritical carbonation process of concrete with coarse aggregates of different shapes and distributions.

\subsection{Random coarse aggregates model and random field of porosity model for concrete}

\subsubsection{Two-dimensional random coarse aggregates model for concrete}

In this Section, a new and effective two-dimensional random coarse aggregate model is proposed to generate random distribution of aggregates in concrete. The generation process consists of the following main steps. 
Step 1: A random distribution of circular aggregates is generated firstly by means of Monte Carlo method to achieve the required mix proportion and aggregate gradation within a given space, from which the locations of the centers and the areas of all the circular aggregates are obtained, as shown in Fig. 3 (a).

Step 2: Similar to the Fourier-Voronoi-based generation of realistic and discrete granular materials ${ }^{[45]}$, the set of the location centers are used as the seeds to generate a set of polygonal Voronoi cells that are individually paired with the circles sharing the same seeds/centers, as shown in Fig. 3 (b).

Step 3: The vertexes of all the Voronoi cells are treated as a series of boundary nodes that are connected by smooth B-spline curves, as shown in Fig. 3 (c). The reduced areas of the modified cells are calculated.

Step 4: A proportional reduction of the areas of the cells enclosed by the closed B-spline curves in Fig. 3 (c) is achieved to generate the pebble aggregates model in Fig. 3 (d). The area reduction is based on the individual ratios of the areas of the paired circular aggregates in Fig. 3 (a) to the cells in Fig. 3 (c).

Step 5: If the aggregates are crushed stones, 4-10 randomly selected points are chosen along the boundary of all the modified Voronio cells. The randomly selected points of a cell in Fig. 3 (c) are connected by a chain of straight lines closing in a loop to transfer the modified cell to a polygon ${ }^{[46]}$. The area of a newly generated polygon is reduced by the ratio of the area of the paired circular aggregate to that of the polygon. This process is repeated for all the cells.

Step 6: If both mixed pebbles and crushed stones are required, Steps 4 and 5 are respectively followed for $m$ randomly selected pebbles and $n$ randomly located crushed stones. An area reduction process is followed then to target the specified area ratio of the respective aggregates. Thus, there are the following three cases.

Case 1: When $n=0$ and $m \neq 0$, it is a two-dimensional concrete model with randomly distributed pebbles only, as shown in Fig. 3 (d).

Case 2: When $m=0$ and $n \neq 0$, it is a two-dimensional concrete model with randomly distributed crushed stones only, as shown in Fig. 3 (e).

Case 3: When $m \neq 0$ and $n \neq 0$, it is a two-dimensional concrete model with randomly distributed pebbles and crushed tones, as shown in Fig. 3 (f).

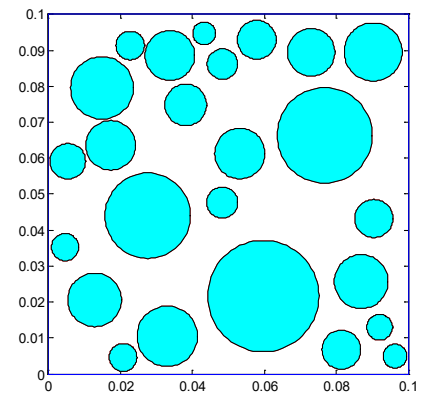

a)

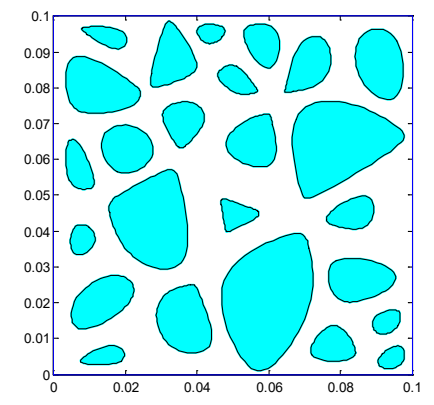

d)

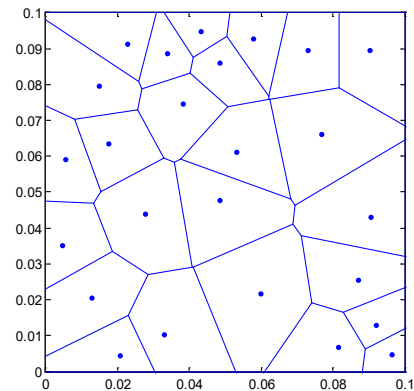

b)

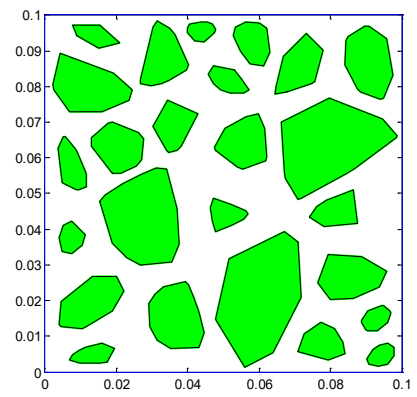

e)

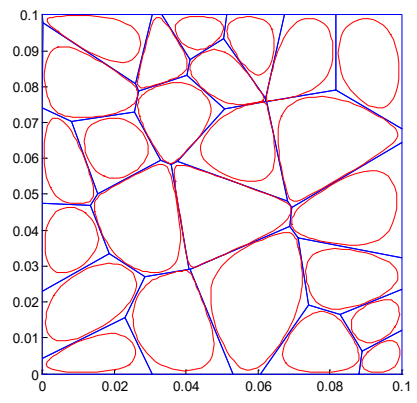

c)

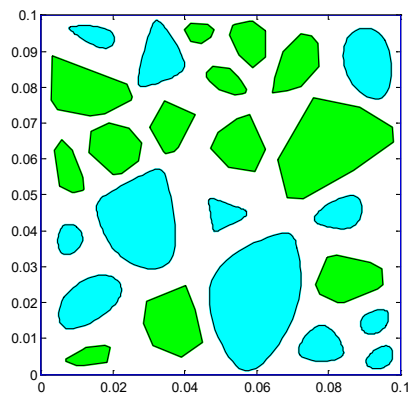

f) 
Fig. 3. The generation of two-dimensional concrete model (m)

The above process has the following features that compare favorably with the existing techniques available in the literature ${ }^{[47-50]}$, which include

1) The two-dimensional random aggregates model can be used to generate pebbles or crushed stones, or a mixture of both.

2) The proposed process does not require dealing with aggregate overlapping that is a common issue when they are randomly distributed in a confined space ${ }^{[51,52]}$. This is because the final distribution of aggregates is established by area reduction of already randomly distributed Voronoi cells.

3) The method to generate two-dimensional random aggregates is simple to implement and extremely computational efficient.

In summary, the process of generating random aggregates in concrete is shown in the flow chart in Fig.4. 


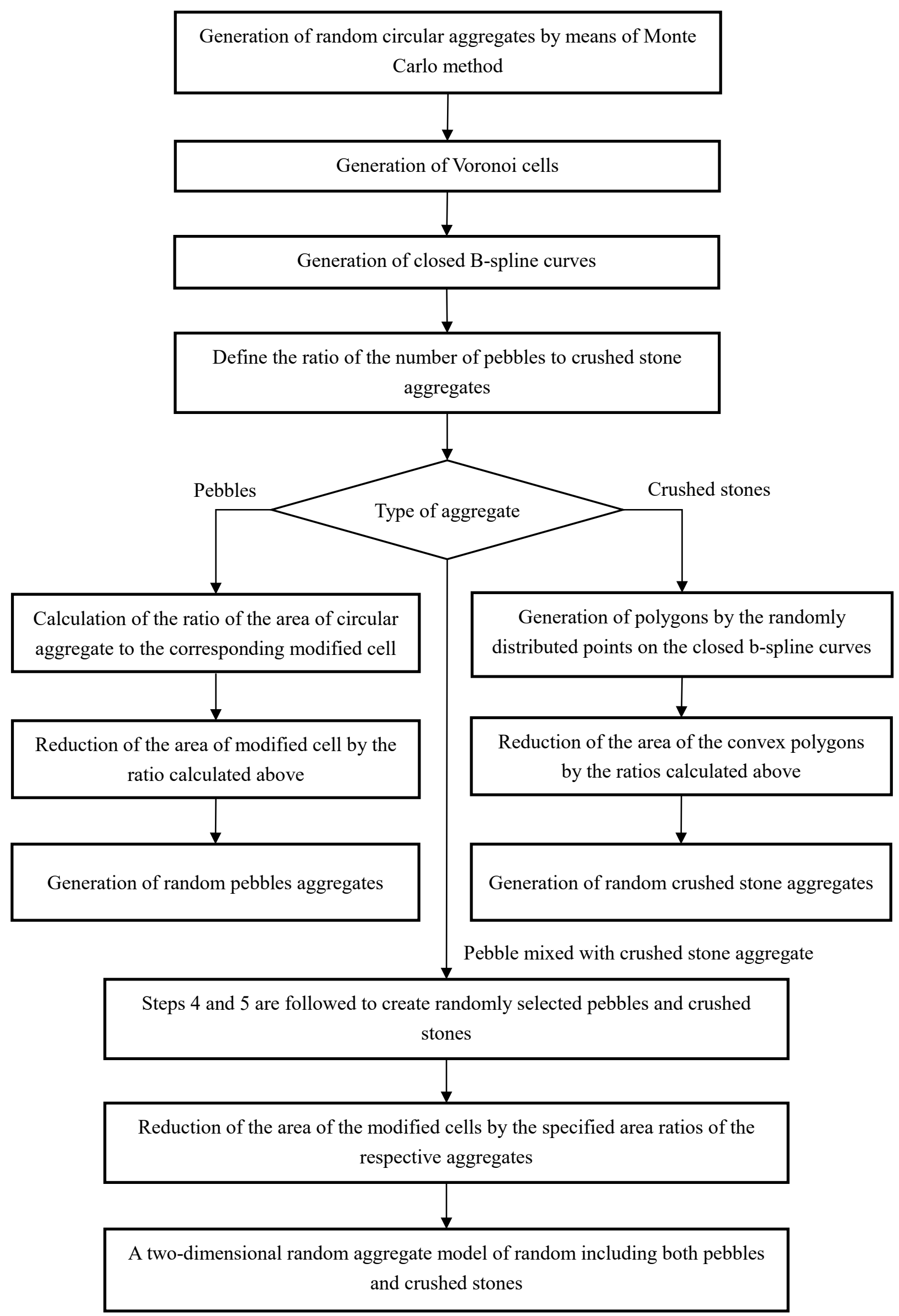

Fig. 4. Flow chart of generating random aggregates model for concrete 


\subsubsection{Random field model of porosity for concrete}

Apart from considering random nature of aggregates, the porosity of cement mortar is also considered in the supercritical carbonation model of concrete using the following spatial correlation function:

$$
\phi(x, y)=\exp \left[-\left(\frac{x^{2}}{a^{2}}+\frac{y^{2}}{b^{2}}\right)^{\frac{1}{1+r}}\right]
$$

where $a$ and $b$ are the autocorrelation lengths in the $x$ and $y$ directions, respectively; $r$ is the roughness factor. Considering that the spatial distribution of porosity is not uniform, it is assumed that the porosity is log-normally distribution and equation (1) is applied to ensure the spatial correlation of porosity. Both Fourier transform and inverse Fourier transform of the above auto-correlation function are then performed in the process of generating random porosity, details of which can be found in $\mathrm{Yu}^{[29]}$. From the simulations and validations in $\mathrm{Yu}{ }^{[29]}$ and $\mathrm{Bao}^{[30]}$, it is appropriate to assume that $a$ and $b$ in equation (1) were both $0.01 \mathrm{~m}$, and $C V_{p}$ in the random fields of porosity model was 0.4 . As an example, a typical random distribution of porosity is shown in Fig. 5 (a). Fig. 5 (b) is a generated random aggregate model of a concrete specimen, where the contour plot shows the porosity distribution of Fig.5(a) with an average of 0.128 from the MIP tests. Considering that the aggregates are relatively impermeable ${ }^{[53]}$, it is reasonable to assume that in the areas occupied by the aggregates the porosity is zero.

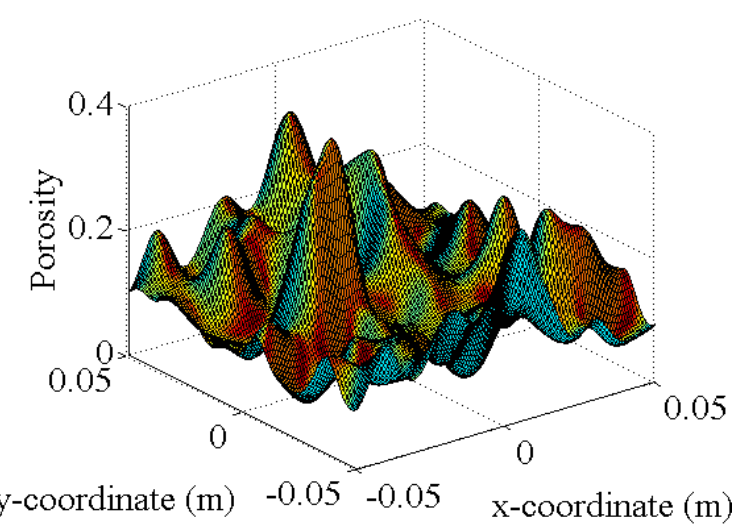

a)

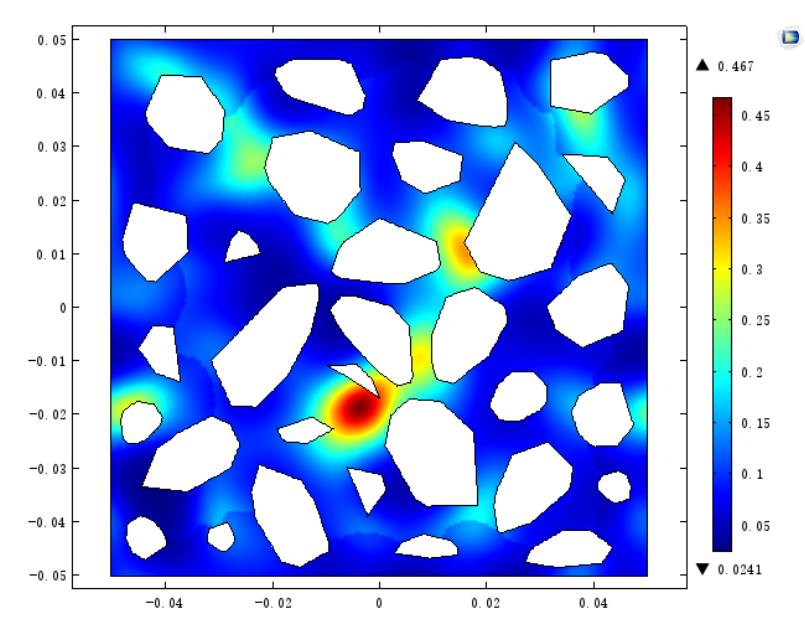

b)

Fig. 5. Random distribution of porosity of cement and randomly distributed aggregates (m)

\subsubsection{Supercritical carbonation model for concrete}

The proposed coarse aggregates model is implemented in the 2-D Multiphysics cement model for simulating cement supercritical carbonation ${ }^{[28]}$, by which the rate of equation of chemical reactions, mass conservation equation, momentum conservation equation and energy conservation equation are solved solved simultaneously using the multi-physics modelling software COMSMOL. The two-dimensional random coarse aggregates and porosity models are introduced to study the effect of coarse aggregates and porosity distribution on the topography of supercritical carbonation depth of concrete.

\subsection{Test verification of supercritical carbonation model of concrete}


In this Section, the effects of aggregates and cement porosity on the supercritical carbonation depth of concrete are studied. The main parameters of concrete are as follows. The intrinsic permeability, $k_{0}$, is $3.0 \times 10^{-21}$ $\mathrm{m}^{2}{ }^{[28,54]}$. The initial average porosity, $n_{0}$, is 0.128 . The relative permeability coefficient, $m$, is $0.4396^{[28,54]}$. The relative humidity, $h_{0}$, is 0.7 , which was measured before the test.

The porosity field is modelled with a fixed autocorrelation lengths $a=b=0.01 \mathrm{~m}$. The coefficient of variation of porosity $C V_{p}$ takes 0.0 and 0.4 for both the uniform $\left(C V_{p}=0.0\right)$ and non-uniform $\left(C V_{p} \neq 0.0\right)$ porosity distributions, respectively, in the simulations below. The random distribution of coarse aggregates generated from the above mentioned two-dimensional random coarse aggregate model are shown in Figs. 6(a-f), where the coarse aggregates are all crushed stone $(m=0)$. Figs. $6(g-l)$ are the carbonation results for uniform porosity distribution. Figs. $6(m-r)$ are the respective carbonation depth for random porosity distribution. The total supercritical carbonation time is 5 hours.

Without loss of generality, only the concrete specimens supercritically carbonated for 5 hours were simulated and twelve samples were studied. For the given coefficients of variation $\left(C V_{p}=0.0\right.$ and 0.4$)$ and autocorrelation length ( $a=b=0.01 \mathrm{~m})$, six random models were generated and simulated.

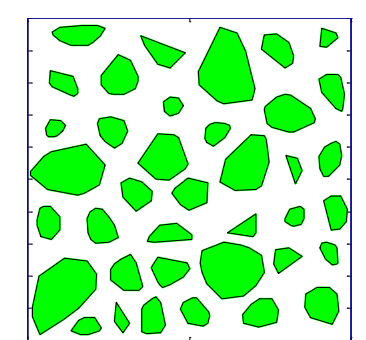

a)

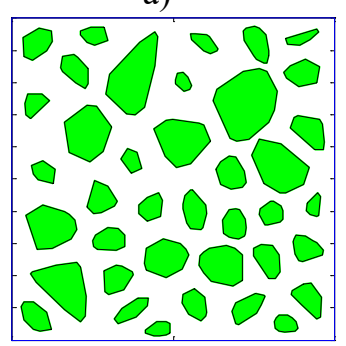

d)

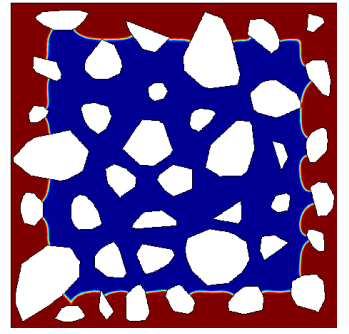

g) Carbonation of model (a),

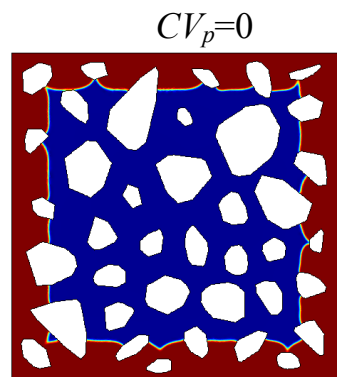

j) Carbonation of model (d),

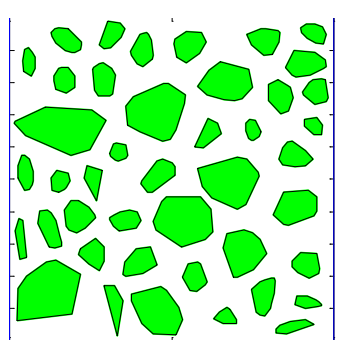

b)

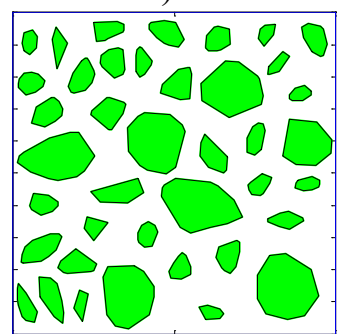

e)

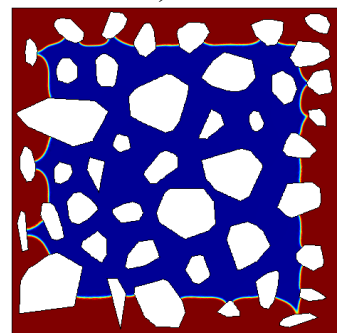

h) Carbonation of model (b), i)

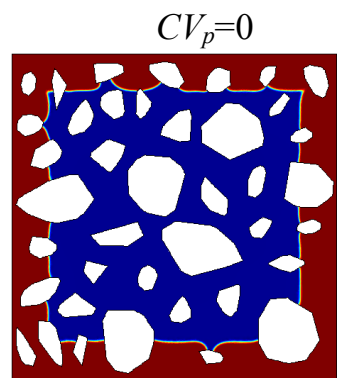

k) Carbonation of model (e), 1)

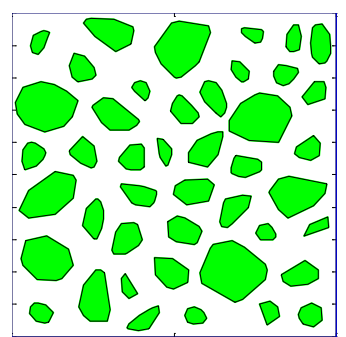

c)

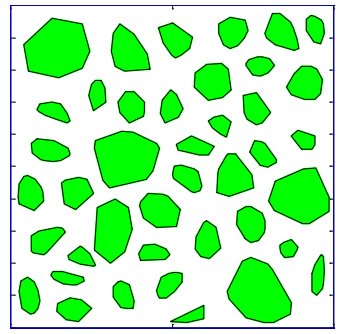

f)

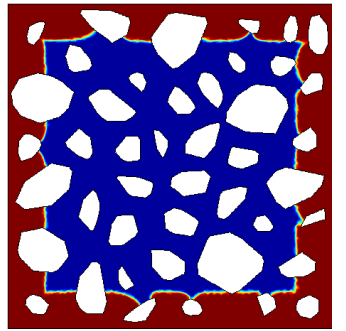

Carbonation of model (c),

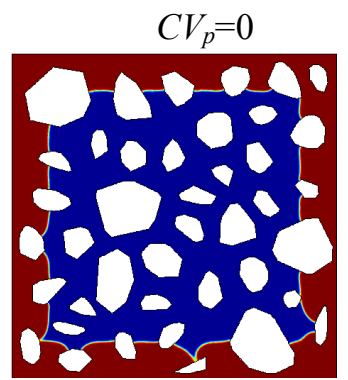

Carbonation of model (f), 


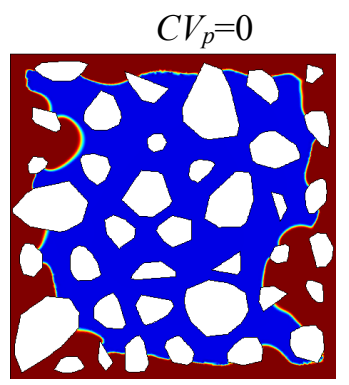

m) Carbonation of model (a)

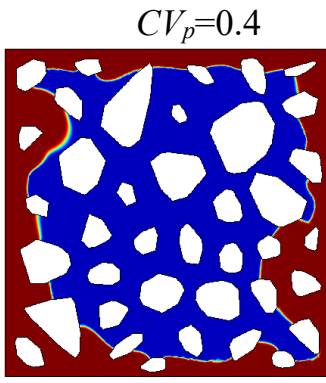

p) Carbonation of model (d), $C V_{p}=0.4$

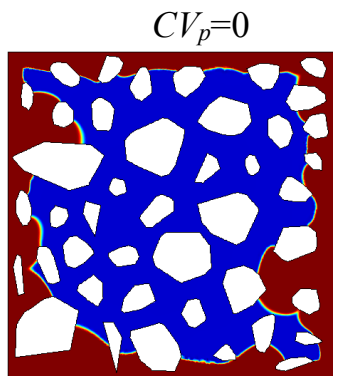

n) Carbonation of model (b),

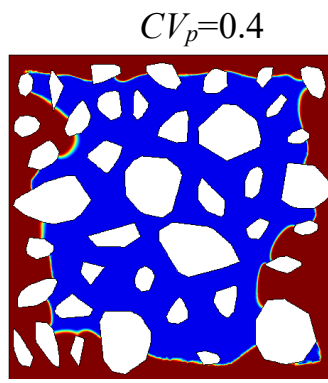

q) Carbonation of model (e) $C V_{p}=0.4$

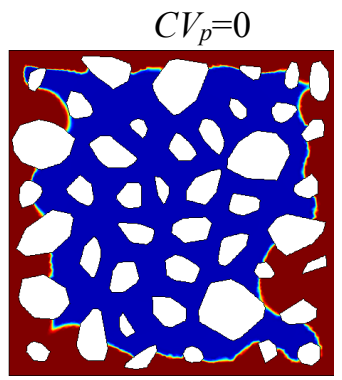

o) Carbonation of model (c), $C V_{p}=0.4$

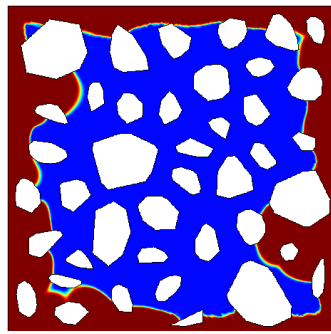

r) Carbonation of model (f),

$C V_{p}=0.4$

Fig. 6. Distribution of coarse aggregates and carbonation results of concrete

The average value of the average, maximum, minimum and variance of carbonation depths are shown in Table 3, where the effect of coarse aggregates on the carbonation results with or without considering random distribution of porosity are compared. When random distribution of porosity is considered, the average carbonation depth is smaller than that when the porosity is considered uniform. It is noticed that in comparison with cement with uniform porosity, after considering random porosity distribution, the maximum carbonation depth is much greater, while the minimum carbonation depth is significantly reduced. It is worthy of mentioning that the variance of carbonation depth, caused by uniform distribution of porosity is 0.8 , which is much smaller than that of considering also random distribution of porosity.

Table 3. Average carbonation depth and variance.

\begin{tabular}{lll}
\hline Distribution of porosity & $\begin{array}{l}\text { Uniform } \\
a=b=0.01 \mathrm{~m}, C V_{p}=0\end{array}$ & $\begin{array}{l}\text { Random } \\
a=b=0.01 \mathrm{~m}, C V_{p}=0.4\end{array}$ \\
\hline Average carbonation depth, $D(\mathrm{~mm})$ & 11.4 & 9.9 \\
Maximum carbonation depth, $D_{\max }(\mathrm{mm})$ & 14.4 & 22.0 \\
Minimum carbonation depth, $D_{\min }(\mathrm{mm})$ & 8.0 & 3.3 \\
Variance of carbonation depth, $v_{l}\left(\mathrm{~mm}^{2}\right)$ & 0.8 & 22.3 \\
\hline
\end{tabular}

The simulation results with different coefficients of variation $\left(C V_{p}=0.0\right.$ and 0.4$)$, supercritical carbonation time $(T=3,4,5 \mathrm{~h})$ and test results are compared and shown in Fig. 7 where the colored bars show the average value of average carbonation depths of concrete and the error bars are the respective minimum and maximum carbonation depths. The results from considering random porosity agree better with the test results than those from without considering random distribution of porosity. 


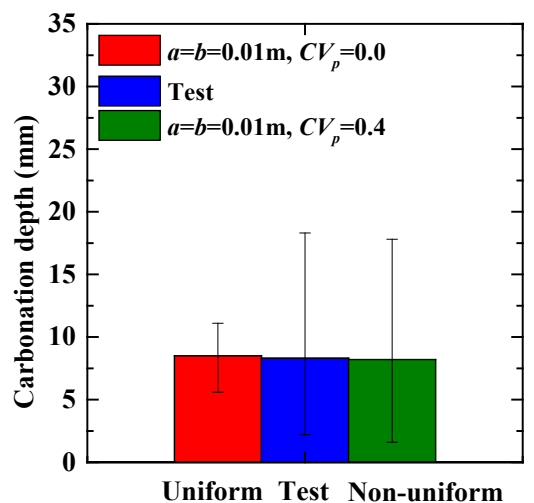

a) Supercritically carbonated for 3 hours

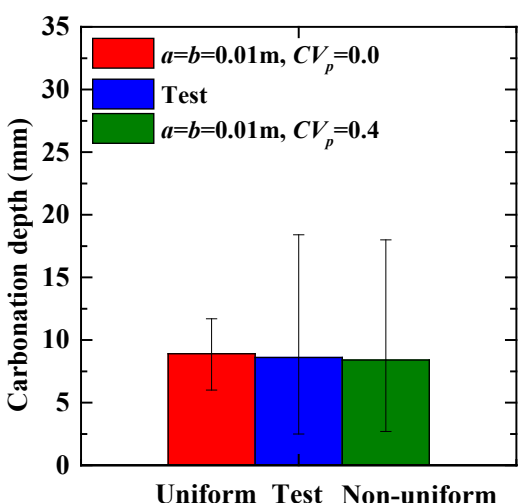

b) Supercritically carbonated for 4 hours

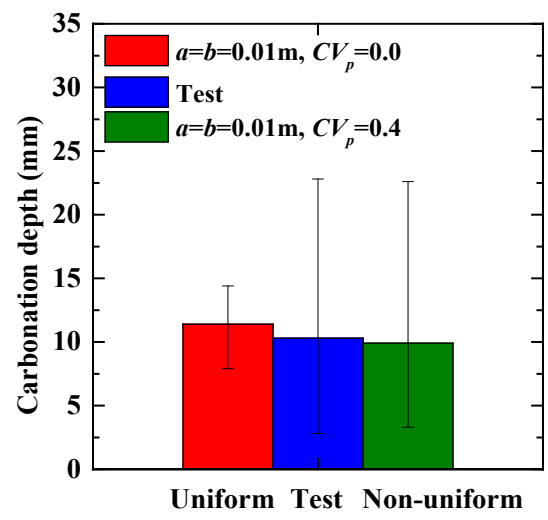

c) Supercritically carbonated for 5 hours

Fig. 7. Verification of the supercritical carbonation model of concrete

In order to study further the effect of coarse aggregates and porosity on the distribution of carbonation depth of concrete, the experimental and simulated carbonation profiles are compared. Fig. 8(a) shows the profile of the carbonation depth of a concrete specimen supercritical carbonated for 5 hours. The distribution of the carbonation depth is irregular and the zoomed-in details show that significant variation of carbonation depth appears not only in the vicinity of the aggregates but also in the cement mortar, which is due to the random distribution of porosity of the mortar. Fig. 8(b) shows the profile of the specimens from the simulation without considering random distribution of porosity. It is clear from the zoomed-in details that the variation of carbonation depth is located mainly in the vicinity of aggregates. Fig. 8(c) presents the simulated carbonation profile of the concrete specimen when random distribution of porosity is also considered. It is evident that the zoomed-in part of Fig. 8(c) shows a more accurate representation of the carbonation profiles observed from the laboratory tests, as it can model the variation of carbonation depth caused by both the distribution of aggregates and the random porosity of cement.

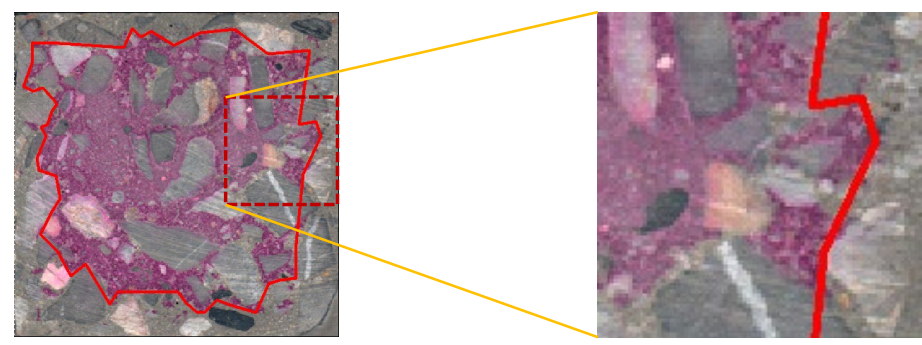

a) Test carbonation profile of concrete block

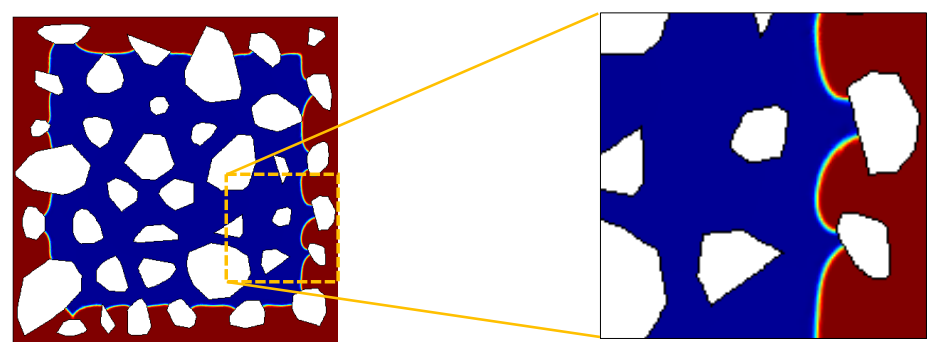

b) Numerical carbonation profile of concrete block $\left(C V_{p}=0\right)$ 


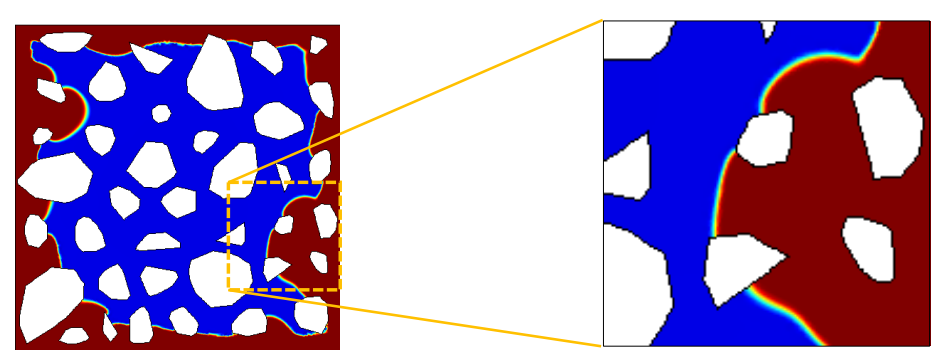

c) Numerical carbonation profile of concrete block $\left(\mathrm{CV}_{p}=0.4\right)$

Fig. 8. Test and simulated carbonation profiles of concrete specimens $(T=5 \mathrm{~h})$

From Fig. 7 and Fig. 8, it can be concluded that by considering random distributions of both aggregates and porosity of cement mortar, the proposed numerical model can be used to predict carbonation depth of the concrete cubes satisfactorily when they are subjected to supercritical carbonation conditions.

\subsection{Effects of type of coarse aggregates on the distribution of irregular carbonation depth}

In order to study the effects of the types of coarse aggregates on the distribution of irregular carbonation depth, random distribution of aggregates with different types of coarse aggregates are generated according to the given mix proportion and aggregate gradation in Section 2. The coarse aggregates are, respectively, circular aggregates only, pebbles only, crushed stone only and pebbles mixed with crushed stones. In the model for pebbles mixed with crushed stone aggregates, it is assumed that the ratio of pebbles to crushed stones is about $1: 1$. For all the four types of coarse aggregates concrete, the average porosity of mortar, $\varepsilon_{m}$, is 0.128 ; the initial intrinsic permeability coefficient of concrete, $k_{0}$, is $3 \times 10^{-21} \mathrm{~m}^{2} ; a=b=0.01 \mathrm{~m} ; C V_{p}$ is 0.4 and the supercritical carbonation time is 5 hours.

Six random models were generated for each of the type of aggregates. The simulated carbonation of one of each is shown in Fig. 9.

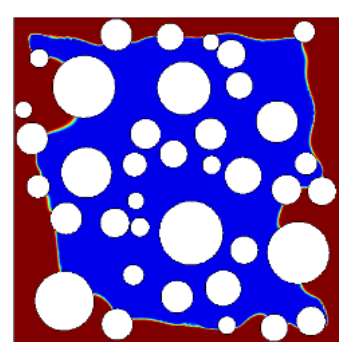

a) Circular aggregates

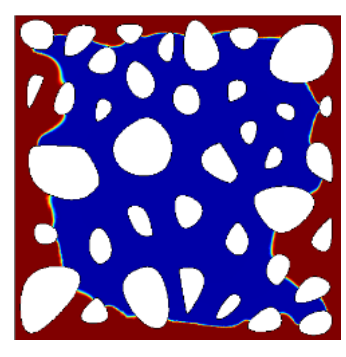

b) Pebble aggregates

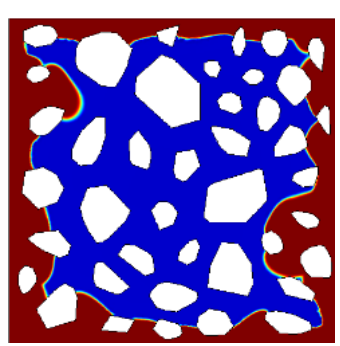

c) Crushed stone aggregates

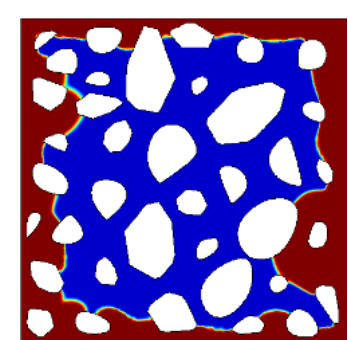

d) Pebble mixed with crushed stone aggregates

Fig. 9. Carbonation of concrete with different coarse aggregates and random porosity distribution

The effects of the type of coarse aggregates on the average carbonation depths and their variance are shown in Fig. 10 (a). It can be observed that in general the type of aggregates has limited impact on the average carbonation depth and the variances are not very significant, while it is obvious that the impact is higher for the concrete with crushed stone aggregates. The coefficient of variation of carbonation depth with different types of coarse aggregates under different carbonation time were statistically analyzed, and the comparisons are shown in Fig. 10 (b). It can be found that the coefficient of variation of carbonation depth with different types of coarse 
aggregates remains virtually unchanged with the increase of carbonation time.

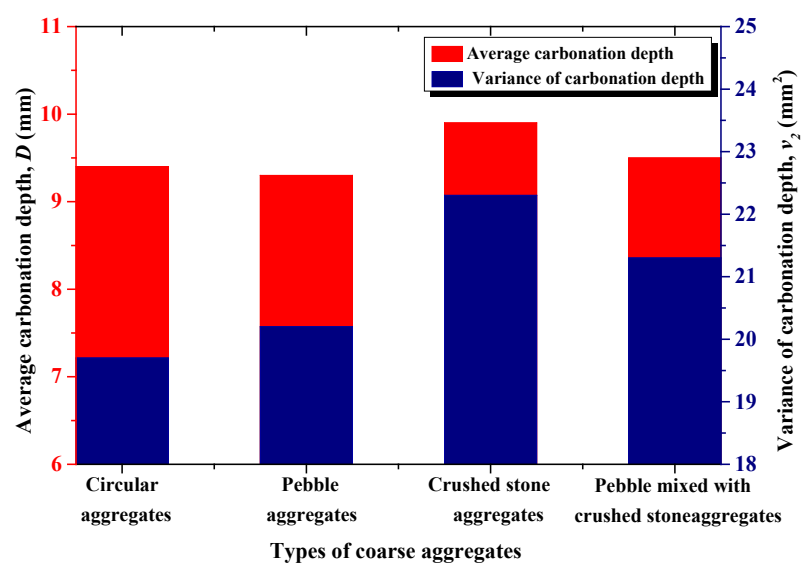

a)

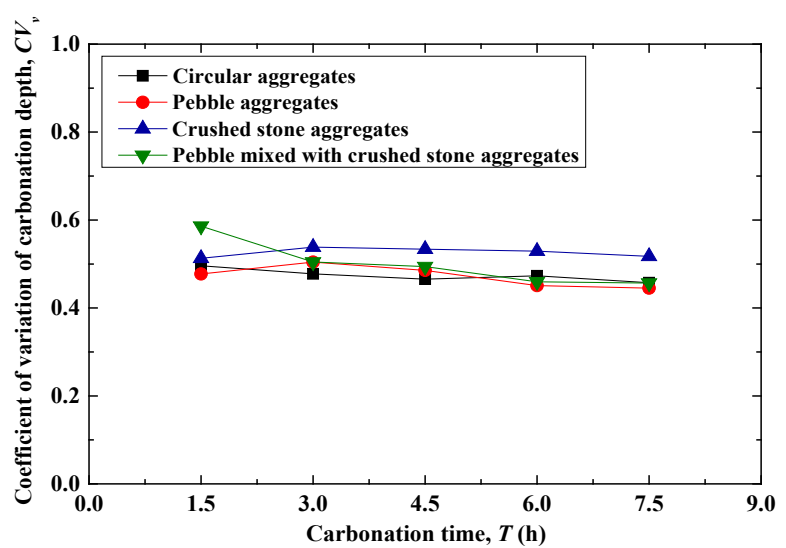

b)

Fig. 10. Effects of coarse aggregates type on the carbonation depth of concrete

\subsection{Effects of volume fraction of coarse aggregates on the distribution of irregular carbonation depth}

In order to study the effects of volume fraction of coarse aggregates on the irregularity of carbonation depth, random distribution of aggregates with different volume fractions of coarse aggregates were generated according to the given aggregate gradation in Section 2. The volume fraction of the coarse aggregates are, respectively, $10.8 \%, 22.8 \%, 31.5 \%$ and $38.2 \%$ according to the target mix proportion. The coarse aggregates are all crushed stones. For all the four cases, the average porosity of mortar, $\varepsilon_{m}$, is 0.128 ; the initial intrinsic permeability coefficient of concrete, $k_{0}$, is $3 \times 10^{-21} \mathrm{~m}^{2} ; a=b=0.01 \mathrm{~m} ; C V_{p}$ is 0.4 and the supercritical carbonation time is 5 hours.

Six random models were generated for each of the volume fractions. One set of the simulation results are shown in Fig. 11.

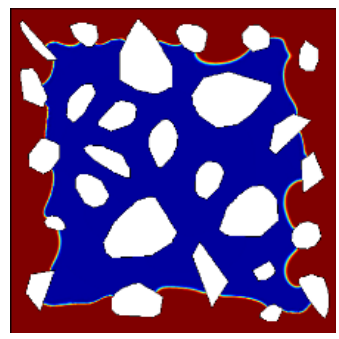

a) $10.8 \%$

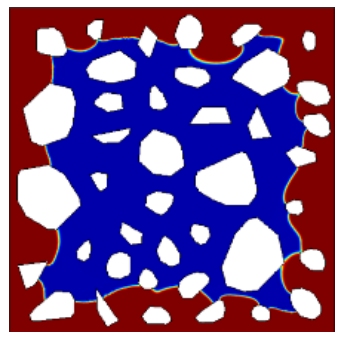

b) $22.8 \%$

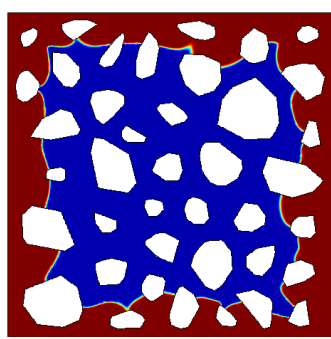

c) $31.5 \%$

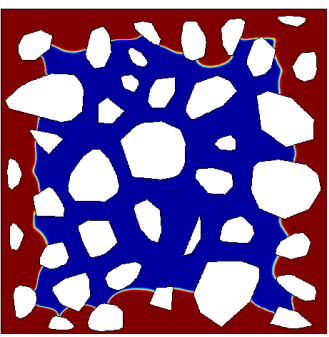

d) $38.2 \%$

Fig. 11. Carbonation profiles of concrete with different volume fractions of coarse aggregates and random porosity

The effects of volume fraction of coarse aggregates on the average carbonation depths and their variance are shown in Fig. 12 (a). It can be observed that in general the effect of volume fraction of coarse aggregates on average carbonation depth and its variance is not very significant. However, the average carbonation depth and its variance of the concrete with $22.8 \%$ coarse aggregates are both greater than those of the concrete with other three volume fraction of coarse aggregates. In order to study the irregularity of carbonation depth of concrete with different volume fraction of coarse aggregates, the coefficient of variation of carbonation depth under different carbonation time were also calculated and compared in Fig. 12 (b). The coefficient of variation of the 
carbonation depth stay more or less the same for all the carbonation times and volume fractions of coarse aggregates.

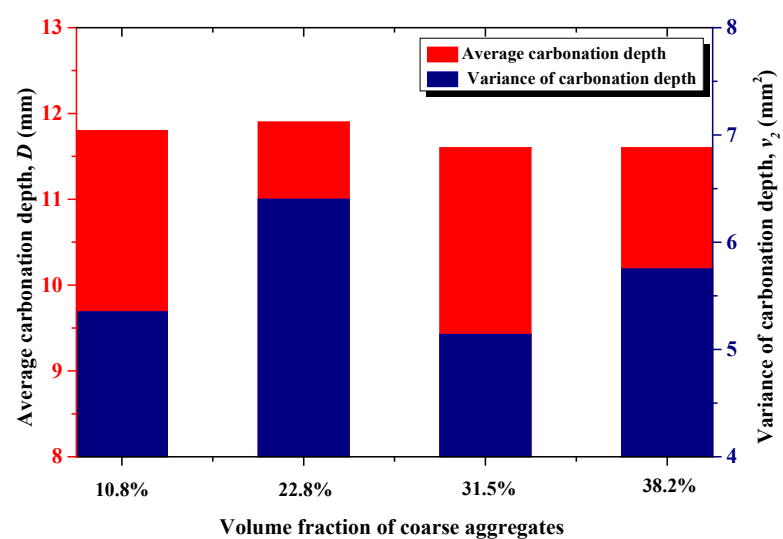

a)

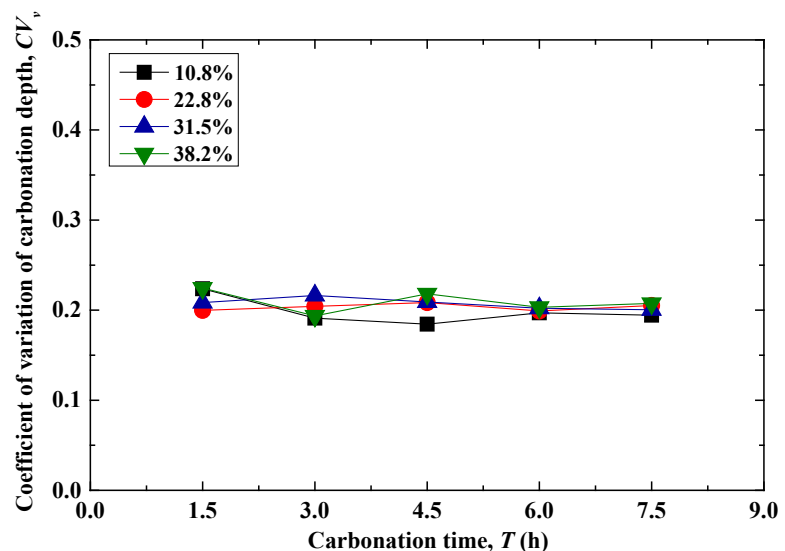

b)

Fig. 12. Effects of volume fraction of coarse aggregates on the carbonation depth of concrete

\subsection{Effects of coarse aggregates gradation on the distribution of irregular carbonation depth}

In order to study the effects of gradation of coarse aggregates on the irregularity of carbonation depth, different gradation of coarse aggregates are generated according to the given mix proportion in Section 2. The gradation of coarse aggregates are, respectively, $2.5 \mathrm{~mm} \sim 5 \mathrm{~mm}$ and $5 \mathrm{~mm} \sim 10 \mathrm{~mm}, 5 \mathrm{~mm} \sim 10 \mathrm{~mm}$ and $10 \mathrm{~mm} \sim 15$ $\mathrm{mm}, 5 \mathrm{~mm} \sim 10 \mathrm{~mm}$ and $10 \mathrm{~mm} \sim 20 \mathrm{~mm}$. The volume fraction of coarse aggregates is $38.2 \%$ and the type of coarse aggregate is crushed stone. For all the three gradation of coarse aggregates, the average porosity of mortar, $\varepsilon_{m}$, is 0.128 ; the initial intrinsic permeability coefficient of concrete, $k_{0}$, is $3 \times 10^{-21} \mathrm{~m}^{2} ; a=b=0.01 \mathrm{~m} ; C V_{p}$ is 0.4 and the supercritical carbonation time is 5 hours.

Six random models were generated for each of the gradation of coarse aggregates. The distribution of cement porosity are from Fig. 5. The simulated carbonation process of one of them is shown in Fig. 13. Fig. 13 (a-c) are the random model of aggregates and carbonation profiles.

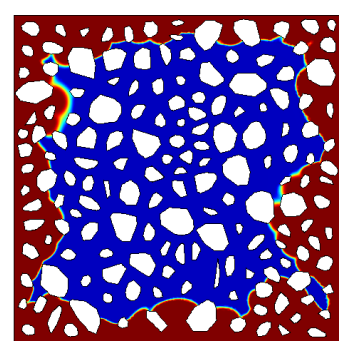

a) $2.5 \mathrm{~mm} \sim 5 \mathrm{~mm}, 5 \mathrm{~mm} \sim 10 \mathrm{~mm}$

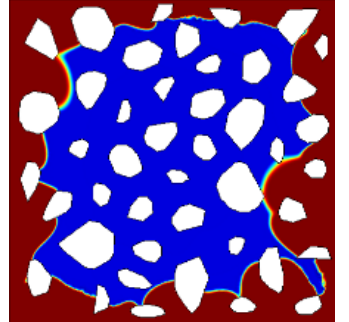

b) $5 \mathrm{~mm} \sim 10 \mathrm{~mm}, 10 \mathrm{~mm} \sim 15 \mathrm{~mm}$

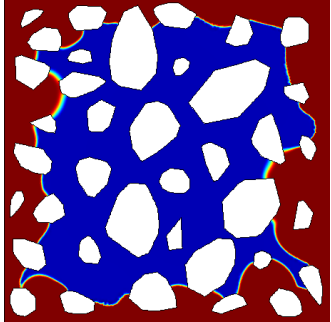

c) $5 \mathrm{~mm} \sim 10 \mathrm{~mm}, 10 \mathrm{~mm} \sim 20 \mathrm{~mm}$

Fig. 13. Carbonation profiles of concrete with different coarse aggregate gradations and random porosity

The effects of gradation of coarse aggregates on the average carbonation depth and the variance are shown in Fig. 14 (a). It can be observed that in general the effect of gradation of coarse aggregates on average carbonation depth and its variance is also not very significant. However, the average carbonation depth and its variance of the concrete with gradations $5 \mathrm{~mm} \sim 10 \mathrm{~mm}$ and $10 \mathrm{~mm} \sim 15 \mathrm{~mm}$ are both greater than those of the concrete with other two gradations. To study the effect of gradation of coarse aggregates on the coefficient of variation of carbonation depth, the above two parameters are evaluated against different carbonation times and coarse aggregate gradations. As shown in Fig. 14 (b), the coefficient of variation of carbonation depth is hardly 
affected by the gradation of coarse aggregates and carbonation time.

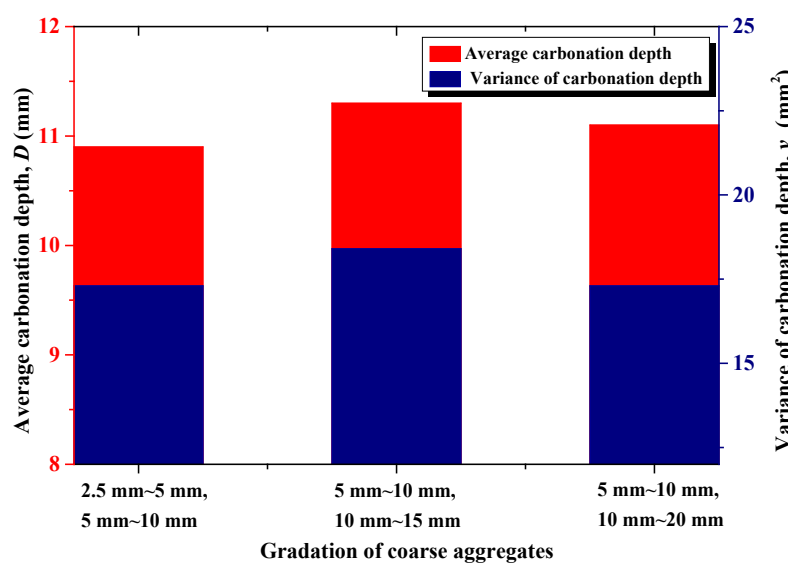

a)

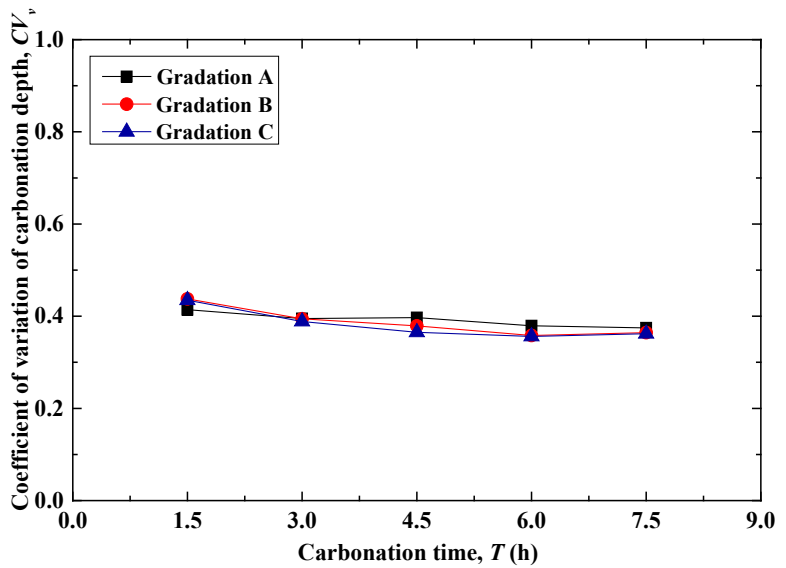

b)

Fig. 14. Effects of coarse aggregate gradation on the carbonation depth of concrete

\subsection{Effects of ITZ on the distribution of irregular carbonation depth}

The thickness and porosity are the two main parameters to characterize the property of ITZ ${ }^{[40]}$. The size of cement grains range from $1 \mu \mathrm{m}$ to $100 \mu \mathrm{m}{ }^{[40]}$ and the thickness of ITZ is normally comparable to the size of cement grains ${ }^{[39]}$. To serve as a pilot study and estimate its maximum impact, an ITZ of $100 \mu \mathrm{m}$ thick was created outside the boundaries of all the randomly shaped and distributed aggregates generated by following the steps described in Section 3.1.1. Previous research has shown that the porosity of the ITZ is greater than that of bulk paste and was estimated up to $40 \%{ }^{[39]}$. In order to study the effects of the porosity of ITZ on the distribution of the irregular carbonation depth, the porosity of the ITZ in this study was assumed to be $19.2 \%, 25.6 \%$ and $32.0 \%$, which are, respectively, 1.5, 2.0 and 2.5 times higher than the porosity of the cement paste (12.8\%). Fig. 15 (a-c) show the carbonation profile of the concrete with ITZ porosity of $12.8 \%, 19.2 \%, 25.6 \%$ and $32.0 \%$, respectively, where Fig. 15 (a) is equivalent to the result without considering existence of ITZ. The porosity of the cement mortar are randomly distributed with a $C V_{p}$ of 0.4 . The supercritical carbonation time is 5 hours. It is clear from Fig. 15 that the carbonation profiles are different for different ITZ porosities.

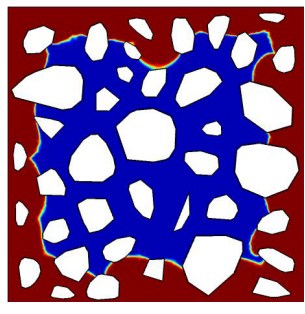

a) $12.8 \%$

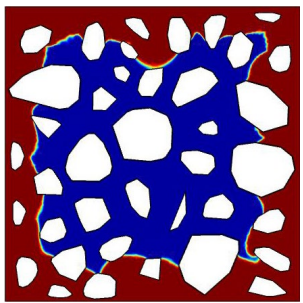

b) $19.2 \%$

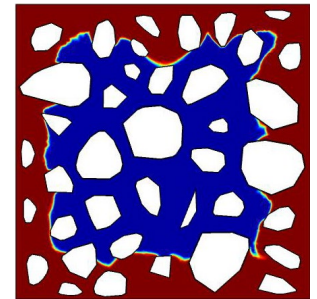

3) $25.6 \%$

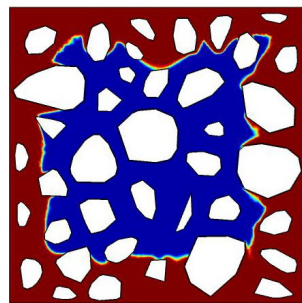

4) $32.0 \%$

Fig. 15. The carbonation profiles of concrete of different ITZ porosities

The effect of ITZ porosity on the maximum, average and minimum carbonation depths are shown in Fig. 16 (a). It is evidence that the ITZ has noticeable effect on the average, maximum and minimum carbonation depth. It appears that predicted maximum and average carbonation depths without considering the effect of ITZ are underestimated, while the effect of ITZ on the minimum carbonation depth is less significant. To study the effect of ITZ porosity on the coefficient of variation of carbonation depth, the coefficient is evaluated against different carbonation times and ITZ porosity. Fig. 16 (b) shows that the coefficient of variation of carbonation depth is hardly affected by the porosity of ITZ and carbonation time. 


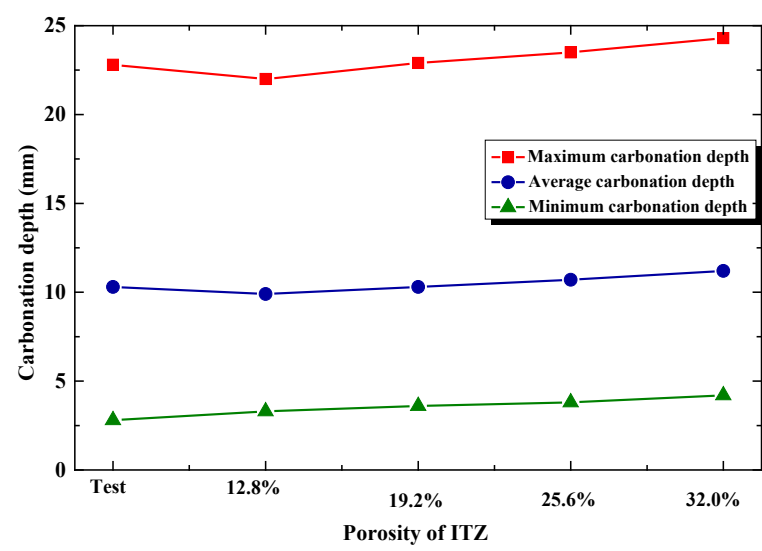

a)

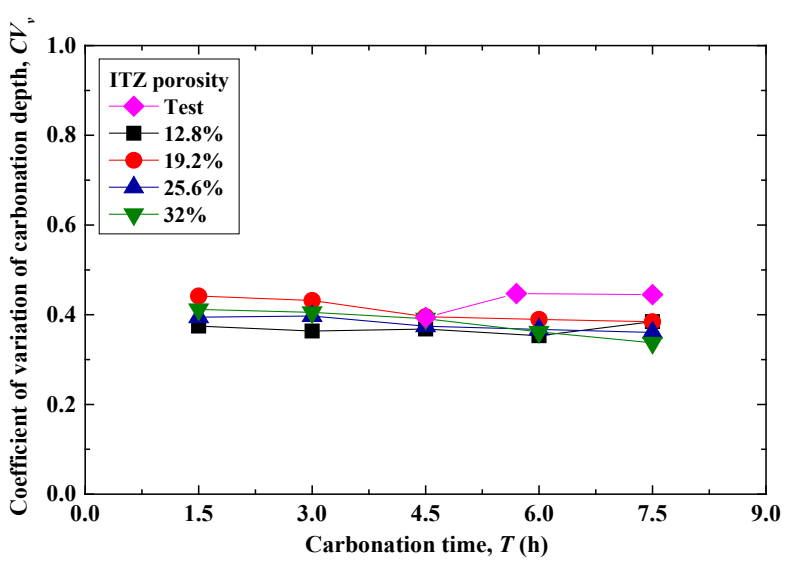

b)

Fig. 16. Effects of ITZ porosity on the carbonation depth of concrete

\section{Conclusions}

Experimental investigations and multi-physics modelling of concrete under supercritical carbonation have been reported. Supercritical carbonation tests on concrete were performed. A novel random coarse aggregates model was proposed and combined with the random porosity model proposed previously by the authors to study the effect of coarse aggregates and porosity on the irregularity of carbonation depth. The effect of types, volume fractions and gradations of coarse aggregates on the average carbonation depth were studied. Their variance and the coefficient of variation of carbonation depth were also studied. Based on the experimental and numerical studies, the main conclusions as follows:

1) The proposed two-dimensional random coarse aggregates model can be used satisfactorily to generate different types of coarse aggregates for required mix proportion and coarse aggregate gradation. It can also generate mixed aggregates of pebbles and crushed stones.

2) When considering only random distribution of coarse aggregates in the supercritical carbonation model, the variance of carbonation depth is smaller than that of the test results. The variance of the simulated carbonation depth is close to the test results by considering random distributions of both coarse aggregates and cement porosity. Thus, the proposed two-dimensional random coarse aggregates model together with the proposed random porosity field can satisfactorily predict the irregularity of carbonation depth statistically.

3) The pilot study on ITZ showed that ITZ has negligible effect on the coefficient of variation of carbonation depth, while an underestimated maximum carbonation depth may be predicted by the model without consideration the effect of ITZ. In principle, however, an increase of porosity in the ITZ will result in an increase of the maximum, average and minimum carbonation depths. Further investigations are required to have better understanding of this relationship.

4) Further researches are also required to include micro cracks in the supercritical carbonation model of concrete.

\section{Acknowledgement}

The authors are grateful for the financial support from the National Natural Science Foundation of China 
(Grant No. 51878518).

\section{References}

[1] Saetta A V, Schrefler B A, Vitaliani R V. The Carbonation of Concrete and the Mechanism of Moisture, Heat and Carbon-Dioxide Flow-through Porous Materials [J]. Cement and Concrete Research, 1993, 23(4): 761-772.

[2] Phung Q T, Maes N, Jacques D, et al. Modelling the Carbonation of Cement Pastes under a $\mathrm{CO}_{2}$ Pressure Gradient Considering both Diffusive and Convective Transport [J]. Construction and Building Materials, 2016, 114: 333-351.

[3] Shah V, Scrivener K, Bhattacharjee B, et al. Changes in Microstructure Characteristics of Cement Paste on Carbonation [J]. Cement and Concrete Research, 2018, 109: 184-197.

[4] Shen J, Dangla P, Thiery M. Reactive Transport Modeling of $\mathrm{CO}_{2}$ through Cementitious Materials under $\mathrm{CO}_{2}$ Geological Storage Conditions [J]. International Journal of Greenhouse Gas Control, 2013, 18: 75-87.

[5] Morandeau A, Thiéry M, Dangla P. Investigation of the Carbonation Mechanism of CH and C-S-H in Terms of Kinetics, Microstructure Changes and Moisture Properties [J]. Cement and Concrete Research, 2014, 56: 153-170.

[6] Singh N, Singh S P. Carbonation and Electrical Resistance of Self Compacting Concrete Made with Recycled Concrete Aggregates and Metakaolin [J]. Construction and Building Materials, 2016, 121: 400409.

[7] Singh N, Singh S P. Carbonation Resistance of Self-Compacting Recycled Aggregate Concretes with Silica Fume [J]. Journal of Sustainable Cement-Based Materials, 2018, 7(4): 214-238.

[8] Singh N, Singh S P. Improving the Carbonation Resistance of Self-Compacting Concrete Containing Recycled Concrete Aggregates using Blended Cements [J]. The Indian Concrete Journal, 2019, 93(4): 4660.

[9] Singh N, Singh S P. Validation of Carbonation Behavior of Self Compacting Concrete Made with Recycled Aggregates using Microstructural and Crystallization Investigations [J]. European Journal of Environmental and Civil Engineering, 2018: 1-24.

[10] Saetta A V, Vitaliani R V. Experimental Investigation and Numerical Modeling of Carbonation Process in Reinforced Concrete Structures [J]. Cement and Concrete Research, 2004, 34(4): 571-579.

[11] Ann K Y, Pack S W, Hwang J P, et al. Service Life Prediction of a Concrete Bridge Structure Subjected to Carbonation [J]. Construction and Building Materials, 2010, 24(8): 1494-1501.

[12] Han J, Liu W, Wang S, et al. Effects of Crack and ITZ and Aggregate on Carbonation Penetration based on 3D Micro X-Ray CT Microstructure Evolution [J]. Construction and Building Materials, 2016, 128: 256271.

[13] Rubin J B, Carey J W, Taylor C. Enhancement of Cemented Waste Forms by Supercritical $\mathrm{CO}_{2}$ Carbonation of Standard Portland Cements [M]//1997: 473-478.

[14] Mo L, Panesar D K. Accelerated Carbonation - a Potential Approach to Sequester $\mathrm{CO}_{2}$ in Cement Paste Containing Slag and Reactive MgO [J]. Cement and Concrete Composites, 2013, 43: 69-77.

[15] Shao Y, Boyd A J, Rostami V. Carbonation Curing Versus Steam Curing for Precast Concrete Production [J]. 2012, 24(9): 1221-1229.

[16] Zhan B, Poon C, Shi C. $\mathrm{CO}_{2}$ Curing for Improving the Properties of Concrete Blocks Containing Recycled Aggregates [J]. Cement and Concrete Composites, 2013, 42: 1-8.

[17] Kou S, Zhan B, Poon C. Use of a $\mathrm{CO}_{2}$ Curing Step to Improve the Properties of Concrete Prepared with Recycled Aggregates [J]. Cement and Concrete Composites, 2014, 45: 22-28.

[18] Chabannes M, Garcia-Diaz E, Clerc L, et al. Studying the Hardening and Mechanical Performances of Rice 
Husk and Hemp-Based Building Materials Cured under Natural and Accelerated Carbonation [J]. Construction and Building Materials, 2015, 94: 105-115.

[19] Santos S F, Schmidt R, Almeida A E F S, et al. Supercritical Carbonation Treatment on Extruded FibreCement Reinforced with Vegetable Fibres [J]. Cement and Concrete Composites, 2015, 56: 84-94.

[20] Pizzol V D, Mendes L M, Savastano H, et al. Mineralogical and Microstructural Changes Promoted by Accelerated Carbonation and Ageing Cycles of Hybrid Fiber-Cement Composites [J]. Construction and Building Materials, 2014, 68: 750-756.

[21] Marinkovi S A B, Ignjatovi I S, Radonjanin V S, et al. Recycled Aggregate Concrete for Structural use an Overview of Technologies, Properties and Applications [Z]. Dordrecht: Springer Netherlands, 2012115130.

[22] Xiao J, Li J, Zhang C. Mechanical Properties of Recycled Aggregate Concrete under Uniaxial Loading [J]. Cement and Concrete Research, 2005, 35(6): 1187-1194.

[23] Zha X, Wang H, Xie P, et al. Leaching Resistance of Hazardous Waste Cement Solidification after Accelerated Carbonation [J]. Cement and Concrete Composites, 2016, 72: 125-132.

[24] Fernandezbertos M, Simons S, Hills C, et al. A Review of Accelerated Carbonation Technology in the Treatment of Cement-Based Materials and Sequestration of $\mathrm{CO}_{2}$ [J]. Journal of Hazardous Materials, 2004, 112(3): 193-205.

[25] Venhuis M A, Reardon E J. Vacuum Method for Carbonation of Cementitious Wasteforms [J]. Environmental Science \& Technology, 2001, 35(20): 4120-4125.

[26] Zha X, Ning J, Saafi M, et al. Effect of Supercritical Carbonation on the Strength and Heavy Metal Retention of Cement-Solidified Fly Ash [J]. Cement and Concrete Research, 2019, 120: 36-45.

[27] Beasley K J. Carbon Dating Concrete Cracks [J]. Journal of Performance of Constructed Facilities, 2015, 29(025140021).

[28] Zha X, Yu M, Ye J, et al. Numerical Modeling of Supercritical Carbonation Process in Cement-Based Materials [J]. Cement and Concrete Research, 2015, 72: 10-20.

[29] Yu M, Bao H, Ye J, et al. The Effect of Random Porosity Field on Supercritical Carbonation of CementBased Materials [J]. Construction and Building Materials, 2017, 146: 144-155.

[30] Bao H, Yu M, Liu Y, et al. Experimental and Statistical Study on the Irregularity of Carbonation Depth of Cement Mortar under Supercritical Condition [J]. Construction and Building Materials, 2018, 174: 47-59.

[31] Samouh H, Soive A, Rozière E, et al. Experimental and Numerical Study of Size Effect on Long-Term Drying Behavior of Concrete: Influence of Drying Depth [J]. Materials and Structures, 2016, 49(10): 40294048.

[32] Chang C, Chen J. The Experimental Investigation of Concrete Carbonation Depth [J]. Cement and Concrete Research, 2006, 36(9): 1760-1767.

[33] Yang C C, Cho S W. Influence of Aggregate Content on the Migration Coefficient of Concrete Materials using Electrochemical Method [J]. Materials Chemistry and Physics, 2003, 80(3): 752-757.

[34] Papadakis V G, Vayenas C G, Fardis M N. Experimental Investigation and Mathematical-Modeling of the Concrete Carbonation Problem [J]. Chemical Engineering Science, 1991, 46(5-6): 1333-1338.

[35] Han J, Liu W, Wang S, et al. Carbonation Reaction and Microstructural Changes of Metro-Tunnel Segment Concrete Coupled with Static and Fatigue Load [J]. Journal of Materials in Civil Engineering, 2017, 29(040162162).

[36] Schutter G. Quantification of the Influence of Cracks in Concrete Structures on Carbonation and Chloride Penetration [J]. Magazine of Concrete Research, 1999, 51(6): 427-435.

[37] Liang M T, Qu W J, Liao Y S. A Study on Carbonation in Concrete Structures at Existing Cracks [J]. Journal of the Chinese Institute of Engineers, 2000, 23(2): 143-153.

[38] Chen M, Wang N, Yu J, et al. Effect of Porosity on Carbonation and Hydration Resistance of CaO Materials 
[J]. Journal of the European Ceramic Society, 2007, 27(4): 1953-1959.

[39] Karen L. Scrivener, Alison K. Crumbie, Peter Laugesen. The Interfacial Transition Zone (ITZ) between Cement Paste and Aggregate in Concrete [J]. Interface Science, 2004, 12: 411-421.

[40] Gao Y, De Schutter G, Ye G, et al. The Itz Microstructure, Thickness and Porosity in Blended Cementitious Composite: Effects of Curing Age, Water to Binder Ratio and Aggregate Content [J]. Composites Part B: Engineering, 2014, 60: 1-13.

[41] Papadakis V G, Fardis M N, Vayenas C G. Effect of Composition, Environmental Factors and CementLime Mortar Coating on Concrete Carbonation [J]. Materials and Structures, 1992, 25(5): 293-304.

[42] Rozière E, Loukili A, Cussigh F. A Performance Based Approach for Durability of Concrete Exposed to Carbonation [J]. Construction and Building Materials, 2009, 23(1): 190-199.

[43] Alahmad S, Toumi A, Verdier J, et al. Effect of Crack Opening on Carbon Dioxide Penetration in Cracked Mortar Samples [J]. Materials and Structures, 2009, 42(5): 559-566.

[44] Ma R, Zhang J, Diao B. Research on the Carbonation Model of Stress Concrete Components [M]//CHING X, DVORIK V. Advances in Intelligent Systems Research, 2015: 191-195.

[45] Mollon G, Zhao J. Fourier-Voronoi-Based Generation of Realistic Samples for Discrete Modelling of Granular Materials [J]. Granular Matter, 2012, 14(5): 621-638.

[46] Huang J, Peng Q, Hu X, et al. A Combined-Alpha-Shape-Implicit-Surface Approach to Generate 3D Random Concrete Mesostructures Via Digital Image Processing, Spectral Representation, and Point Cloud [J]. Construction and Building Materials, 2017, 143: 330-365.

[47] Sobolev K, Amirjanov A. Application of Genetic Algorithm for Modeling of Dense Packing of Concrete Aggregates [J]. Construction and Building Materials, 2010, 24(8): 1449-1455.

[48] Wriggers P, Moftah S O. Mesoscale Models for Concrete: Homogenisation and Damage Behaviour [J]. Finite Elements in Analysis and Design, 2006, 42(7): 623-636.

[49] T Xinwei, Z Chuhan. Simulation of meso-fracture for concrete based on the developed random aggregate model[J]. Journal of Tsinghua University (Science and Technology), 2008(3): 348-351, 356. (in Chinese)

[50] X Yidong, Z Yingying, Du Kun, et al. Meso-scale finite element simulation of corrosion-induced cracking in reinforced concrete cover [J]. Journal of Southeast University (Natural Science Edition), 2017(2): 356361. (in Chinese)

[51] Wittmann F H, Roelfstra P E, Sadouki H. Simulation and Analysis of Composite Structures [J]. Materials Science and Engineering, 1985, 68(2): 239-248.

[52] De Schutter G, Taerwe L. Random Particle Model for Concrete Based on Delaunay Triangulation [J]. Materials and Structures, 1993, 26(2): 67-73.

[53] Li L. A Pore Size Distribution-Based Chloride Transport Model in Concrete [J]. Magazine of Concrete Research, 2014, 66(18): 937-947.

[54] Mainguy M, Coussy O, Baroghel-Bouny V. Role of Air Pressure in Drying of Weakly Permeable Materials [J]. Journal of Engineering Mechanics-ASCE, 2001, 127(6): 582-592. 